\title{
The Empirical Study of Parents Perceptions on Exposure of Expert System to Recognize The Children Disease
}

\author{
K. Adiyarta ${ }^{1}$, C. Simon ${ }^{1}$, T. Fatimah ${ }^{2}$ \\ \{krisna.adiyarta@budiluhur.ac.id ${ }^{1}$, chris_simon92@yahoo.com ${ }^{1}$, titin.fatimah@budiluhur.ac.id ${ }^{2}$ \} \\ Program Studi Magister Ilmu Komputer Universitas Budi Luhur, Jakarta, Indonesia ${ }^{1}$, \\ Program Studi Teknik Informatika Fakultas Teknologi Informasi Universitas Budi Luhur, Jakarta, \\ Indonesia $^{2}$
}

\begin{abstract}
The development of computers has transformed many changes very rapidly nowadays, it is simultaneously with the increasingly complex human needs. The advancement of an expert system is concerned to be used by parents to assist them in efforts to detect early childhood illnesses before medical treatment is done. This study aims to obtain a conclusion of measurement of acceptance of pediatric disease expert system. The partial testing of perceived is established usefulness and perceived ease of use variables has a positive result on attitude toward using on system usage. The positive influence is interpreted the better the perceived usefulness perceived user (user perceived usefulness) formed the more assured the attitude of the user (attitude toward using) in using the system. On the contrary, the research results is shown the perceived ease of use has no positive result on actual system usage on system usage. This is because the user response to the way the operation of the system is still said to be complicated and inflexible.
\end{abstract}

Keywords: Expert System, Children Disease, perceived usefulness, perceived ease of use, attitude toward using, actual system usage

\section{Introduction}

The computer advancement has undergone many changes very rapidly, along with the increasingly complex human needs. Computers have been used broadly in various fields now, for example: business, healthcare, education, psychology, games and so on. The experts are encouraged to further to develop computers in order to help human work or even exceed the ability of human labor.

Health is a valuable thing for humans because they experiences health problems. Children are very defenseless to germs and a lack of sensitivity to the symptoms of a disease is a fear for the parents themselves. The general parents are not always trained medically so they are less able to understand the sign of a disease and determine it. The allegedly system computer construction can be utilized by parents to solve this problem.

The expert system (ES) is an area of artificial intelligence (AI), and advanced by the artificial intelligence society in the midle of 1960s. The behind fundamental idea of Expert System is simply transferred skill from human to computer expertize. The information is stored on the computer and the user requests specific recommendation from the computer as 
required. Computers can think and come to certain conclusions. Then, like a consultant, it advises and explains, if asked, the logic behind the suggestion [1]. The Expert System, the AI core, is defined by Edward Feigenbaum of StanfordUniversity as "an intelligent computer program that uses knowledge and inference procedures to solve quite difficult problems that require significant human expertise for their solutions". This definition is understood as one of the most accepted definitions of Expert Systems [2]. In its development, the Expert Support System (MDSS) is an emerging technology that can improve the accuracy of diagnostic decisions by enhancing the natural capabilities of human diagnostic experts in complex medical diagnostic processes [3].

The theoretically fact is the computer is able to solve problems on the other hand the necessity of systems that can help parents in detecting the disease of children. It will confirm the results of disease analysis based on temporary symptoms to the parents then need to develop the system by placing the user needs as a basis of consideration. Evaluating a user's acceptance system is an important step in order to perform for a successful system development. This study aims to obtain a conclusion of measurement of acceptance of pediatric disease expert system.

\section{Related Research}

The previous studies have been considerably attempted to measure the extent to which the intelligent system is acceptable to the user community. Davis (1993) in his research discusses the reason users accept or reject the information system and method user acceptance is typically affected by the features of the design of the built system. The field study is applied of 112 users against two systems was established to examine hypothetical models through questionnaires. The results concluded that attitudes toward use, perceived usefulness and perceived ease of use fully mediate the effect of system design features on their use [4]. Horan et al., (2004) established a model of concept for online detection of systems by physicians and examined the socio-structural model of work using a national look at of 141 physicians [5]. Zheng (2006) uses an approach that mixing the evaluation by combining the quantitative model development trajectories with qualitative assessment to analyse the adoption of clinical measurement technology and leprosy acceptance behavior [6]. Al-Nassar et al., (2011) investigated several factors that influence the use of EMR in Jordan and consequently provide the right conclusions for decision-makers to consider applying a better EMR system. From the analysis, it shows that there is a significant association among new technology and perceived technology that makes peoples believe that health care professionals look after to consider adopting new technology as a positive as long as it results in improved efficiency and quality [7]. Gallant et al., (2010) studied the website at the hospital and concluded that all factors such as perceived usefulness, perceived ease of use, trust and privacy are highly relevant to the ehealth context [8]. Esmaeilzadeh et al., (2013) identifies several factors that influence the adoption of Health Information Technology professionals (IT). pediatric disease expert system [9]. 


\section{The Research Method}

The explanatory research is used and built a prototype of an expert system used to detect childhood illness. The researchers install the Dempster Shafer theory in our prototype [10]. Shafer's Dempster theory is a combination, representation and propagation of uncertainty, the theory has some characteristics that are institutive in accordance with the way an expert thinks. In general the Dempster Shafer theory is written in an interval: [Belief, Plausibility]. Belief (Bel) is a measure of the strength of evidence in favor of a set of propositions. If the value is 0 then indicates that there is no evidence, and if value 1 indicates a certainty. Plausibility (Pls) reduces the level of certainty of the evidence. Plausibility is 0 to 1 . If $\mathrm{X}$ is convinced, it can be said that $\operatorname{Bel}(X)=1$, so the above formula values from Pls $(X)=0$.

The study will explain the causal relationship between research variables through hypothesis testing. It will test the hypothesis proposed and expected to expound the relationship and influence of the variables. The quantitative approach is used of surveys were conducted in an effort to collect primary data. Primary data was obtained by distributing questionnaires to a number of respondents who previously had tried to use a prototype built system. The questionnaire contains some statements and questions. The research is used Technological Acceptance Model (TAM) model to analyze factors influencing acceptance of system usage [11]. Hypothesis testing is done by using path analysis (path analysis) as the development of multiple regression analysis with significance level $=0.05$. Figures 1 and 2 show the research model. There are two substructure that must be tested are:

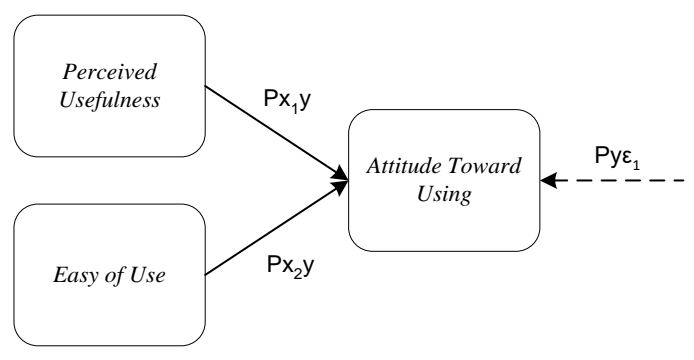

Fig. 1. Substructure 1 on Y.

Sub structural 1 tested the effect of perceived usefulness (X1), perceived ease of use (X2) to attitude toward using (Y).

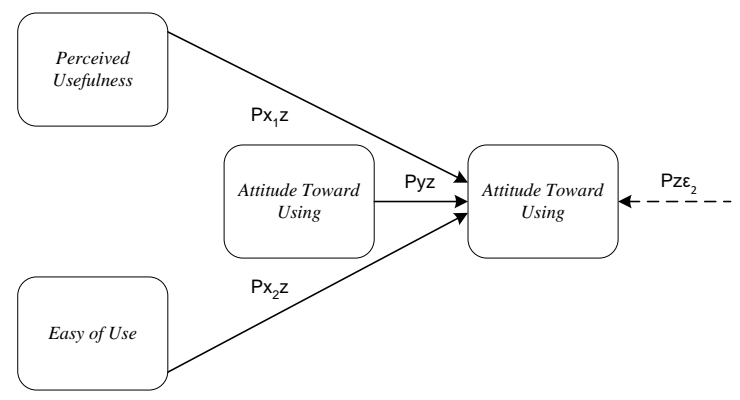

Fig. 2. Substructure 2 against $\mathrm{Z}$ 
Substructure 2 which tests the effect of perceived usefulness (X1), perceived ease of use (X2) and attitude toward using (Y) against actual system usage (Z).

Indicators of each of the collisions used in this study are presented in table 1. Measurements to the items of each indicator using the Likert scale of 5 points. Likert scale is used to measure attitudes, opinions and perceptions of a person or group of people against each indicator in a range of scales.

\section{Result and Discussion}

The primary data is obtained from the spread of questionnaires or specified questionnaires sample as has been previously stated. The questionnaire was made in Bahasa Indonesia and printed 100 questionnaires. Questionnaires were distributed to married people, have children and they are applied to manage the electronics device such as smartphones or computers in Kosambi district, Tangerang. Questionnaires were distributed twice. The first questionnaire distributed to approximately 50 respondents, the results of the questionnaire is tested the validity and reliability test using SPSS software (Statistical Product and Service). If the test results meet the desired criteria then the dissemination done to 50 other respondents.

Table 1. Constructive research indicators

\begin{tabular}{llc}
\hline \multicolumn{1}{c}{ Construct } & \multicolumn{1}{c}{ Indicator } & $\begin{array}{c}\text { No } \\
\text { Item }\end{array}$ \\
\hline perceived & Work more quickly & 1 \\
usefulness & Job Performance & 2 \\
& Increase productivity & 3 \\
& Effectiveness & 4 \\
& Makes job easier & 5 \\
perceived ease & Useful & 6 \\
of use & Ease of learning & 7 \\
& Controllable & 8 \\
& Understandable and clear & 9 \\
& Flexible & 10 \\
attitude & Ease of understanding & 11 \\
toward using & Easy to use & 12 \\
& Interacted comfortably & 13 \\
& Applied delightfully & 14 \\
actual system & Managed Enjoyably & 15 \\
usage & Interesting & 16 \\
& Applied fully & 17 \\
& Frequency of use & 18 \\
& Satisfaction of use & 19,20 \\
\hline
\end{tabular}

Referred on the respondents' responses on the results of the questionnaire data collected, the validity tests results are conducted using software SPSS (Statistical Product and Service) is presented in table 2 .

Based on the responses of respondents on the results of the questionnaire data collected, the reliability test performed using software SPSS (Statistical Product and Service). The results obtained for reliability testing are presented in Table 3. 
The Heteroscedasticity tests were performed to define the residual observation variance inequality was observed to another. Based on the responses of respondents on the results of data collected questionnaires. The test result is conducted using SPSS software. (Statistical Product and Service) is shown in Figure 3.

The simultaneous influence test is used to expose the independent variables synchronously or simultaneously affect the dependent variable. Based on the responses of respondents on the results of the questionnaire data collected and the simultaneous hypothesis test results are presented in table 4 (substructure 1) and table 5 (substructure 2).

Table 2. Instrument validity test results.

\begin{tabular}{llll}
\hline Variable & $\begin{array}{l}\text { Question } \\
\text { Code }\end{array}$ & $\begin{array}{l}\text { Person } \\
\text { Product }\end{array}$ & Criteria \\
\hline perceived & PU1 & .623 & High \\
usefulness & PU2 & .515 & Moderate \\
& PU3 & .633 & High \\
& PU4 & .617 & High \\
& PU5 & .523 & Moderate \\
perceived ease of & PU6 & .534 & Moderate \\
use & PEOU1 & .546 & Moderate \\
& PEOU2 & .616 & High \\
& PEOU3 & .648 & High \\
& PEOU4 & .629 & High \\
& PEOU5 & .671 & High \\
attitude toward & PEOU6 & .617 & High \\
using & ATU1 & .560 & Moderate \\
& ATU1 & .527 & Moderate \\
& ATU1 & .471 & Moderate \\
attitude toward & ATU1 & .492 & Moderate \\
using & ASU1 & .694 & High \\
& ASU2 & .599 & Moderate \\
& ASU3 & .610 & High \\
& ASU4 & .659 & High \\
\hline
\end{tabular}

Table 3. Instrument reliability test results.

\begin{tabular}{lll}
\hline \multicolumn{1}{c}{ Variable } & $\begin{array}{c}\text { Cronbach's } \\
\text { Alpha }\end{array}$ & Description \\
\hline X1: perceived usefulness & .812 & Reliable \\
X2: perceived easy of use & .842 & Reliable \\
Y1: attitude toward using & .723 & Reliable \\
Z1: actual system usage & .817 & Reliable \\
\hline
\end{tabular}




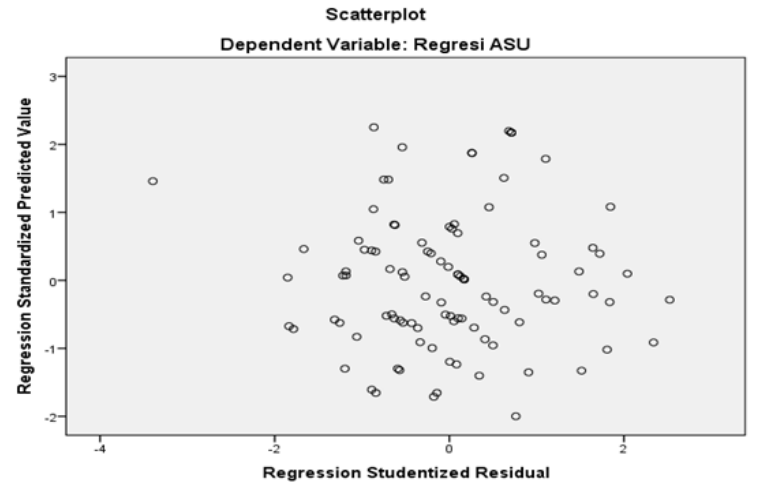

Fig. 3. Results scatter plot heteroscedasticity test.

Table 4. Simultaneous hypothesis test results sub structure1.

\begin{tabular}{lrrrrr}
\multicolumn{6}{c}{ ANOVA $^{\text {a }}$} \\
\hline Model & $\begin{array}{c}\text { Sum of } \\
\text { Squares }\end{array}$ & df & $\begin{array}{c}\text { Mean } \\
\text { Square }\end{array}$ & F & Sig. \\
\hline Regresion & 77.610 & 2 & 38.805 & 175.978 & $.000^{\mathrm{b}}$ \\
1 Residual & 21.390 & 97 & .221 & & \\
Total & 99.000 & 99 & & & \\
\hline
\end{tabular}

a. Dependent Variable: Regression ATU

b. Predictors: (Constant), Regression PEOU, Regression

PU

Table 5. Results of sub structural simultaneous hypothesis test 2.

\begin{tabular}{lrrrrr}
\multicolumn{6}{c}{ ANOVA $^{\text {a }}$} \\
\hline Model & $\begin{array}{l}\text { Sum of } \\
\text { Squares }\end{array}$ & df & $\begin{array}{c}\text { Mean } \\
\text { Square }\end{array}$ & F & Sig. \\
\hline Regresion & 49.501 & 3 & 16.500 & 32.001 & $.000^{\mathrm{b}}$ \\
1 Residual & 49.499 & 96 & .516 & & \\
$\quad$ Total & 99.000 & 99 & & & \\
\hline a. Dependent Variable: Regression ASU & \\
b. Predictors: (Constant), Regression ATU, Regression PU, \\
Regression PEOU
\end{tabular}

The Sig value is shown in the ANOVA table of $0.000 \mathrm{~b}$. Meanwhile, The ANOVA table has a value smaller than the significant value that has been set that is 0.005 based on table 4 and table 5. It can be concluded that there is influence between independent variables together to dependent variable and individual testing can be done.

The Individual influence test is applied to determine the partial influence of independent variables to the dependent variable. the results of individual hypothesis testing is presented in table 6 (substructure 1) and table 7 (substructure 2), it is reflected on the responses of respondents on the results of the questionnaire data collected 
Table 6. Individual hypothesis test results sub structure 1.

\begin{tabular}{lrrr}
\hline \multicolumn{1}{c}{ Model } & $\begin{array}{c}\text { Standardized } \\
\text { Coefficients } \\
\text { Beta }\end{array}$ & \multicolumn{1}{l}{ T } & Sig. \\
\hline $\begin{array}{l}\text { (Constant) } \\
\text { Regression }\end{array}$ & .334 & 5.051 & .000 \\
$1 \quad \begin{array}{l}\text { PU } \\
\text { Regression } \\
\text { PEOU }\end{array}$ & .619 & 9.360 & .000 \\
\hline
\end{tabular}

a. Dependent Variable: Regression ATU

The results is shown the Sig value Based on table 6. PU regression in the table of 0.000 , where the value of Sig. in the table has a value smaller than the predefined significance value of 0.05 , so it can be achieve the influence of variable perceived usefulness toward attitude toward using variable on the use of expert system diagnosis of child disease and Sig value. PEOU regression on the table of 0.000 , so it can be concluded that there is influence of perceived ease of use variable to attitude toward using variable on the use of expert system diagnosis of childhood disease.

The results is shown the Sig value Based on table 7. PU regression in the table of 0.000 , where the value of Sig. in the table has a value smaller than the predefined significance value of 0.05 , so it can be concluded that there is influence of perceived usefulness variable to actual system use variable on the use of expert system diagnoses childhood disease and Sig value. PEOU regression in the table of 0.732 , so it can be concluded that there is no effect of perceived ease of use variable against actual system use variable on the use of expert system diagnosis of childhood disease and Sig value. ATU regression in the table of 0.631 , so it can be concluded that there is no effect of attitude toward using variable on actual system use variable on the use of expert system diagnosis of childhood disease.

The comprehensive influence of each variable can be seen from the path diagram presented in figure 4 .

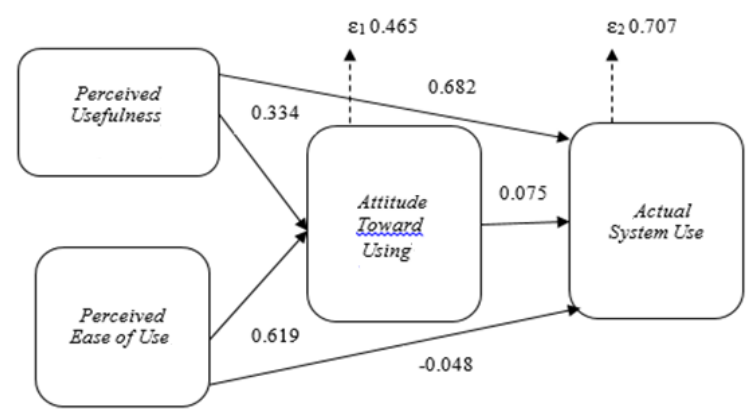

Fig. 4. Results of Line Chart Analysis 


\section{Conclusion}

After confirming and testing of the hypothesis, the research results can be concluded as follows:

1. The partial testing of perceived usefulness variables has a positive effect on attitude toward using on system usage. The interpretation positive influence gives the better the perceived usefulness perceived user (user perceived usefulness) formed the more assured the attitude of the user (attitude toward using) in using the system.

2. The partial testing of perceived usefulness variables has a positive effect on attitude toward using on the use. The interpretation positive influence gives the better the perceived user perception of perceived (perceived ease of use) that is formed then the more confident the attitude of the user (attitude toward using) in using the system.

3. The partial testing of perceived usefulness variables has a positive effect on actual system usage on system usage. This means that the more productive a system is made, the higher the frequency of users accessing the system. These attitudes and behaviors will then affect the intentions of the users to use the future diagnostic disease system of children in the future.

4. The partial testing of attitude toward using variable has no positive effect on actual system usage on system usage. This is probably because the user is still less confident with the results released by the system. The average interpretation of each indicator for attitude toward using variable is good in data.

5. The simultaneous testing is found perceived usefulness variables, perceived ease of use and attitude toward using on actual system usage had a positive impact on system usage.

6. The partial testing of perceived ease of use variables did not have a positive effect on actual system usage on system usage. This is because the user response to the way the system's operation is still said to be complicated and inflexible.

\section{Limitations and Further Research}

Technological Acceptance Model is most extensively accepted by many researchers but this study can be made substantially after the actual expert systems are built and surveyed to ensure actual acceptability and it is not just related on their attitude to the prototype built in this study so that there is a real picture. This will further enhance the testing of the expert system's effectiveness, usability and functionality and the quality of information.

Moreover, it is recommended to develop the new models and utilized the power of the Technological Acceptance Model and throw away its weaknesses. For an important work, geopolitical zones must be considered in the future to gain a broader view of the attitudes and opinions of the public towards the application of expert systems. 


\section{References}

[1]E. Turban, J. E. Aronson, and T.-P. Liang, Decision Support Systems and Intelligent Systems, 7th ed. New Jersey: Prentice Hall, 2005.

[2]E. C. Ogu and Y. A. Adekunle, "Basic Concepts of Expert System Shells and an Efficient Model for Knowledge Acquisition,” Int. J. Sci. Res., vol. 2, no. 4, pp. 554-559, 2013.

[3]D. West, P. Mangiameli, R. Rampal, and V. West, "Ensemble Strategies for a Medical Diagnostic Decision Support System: A Breast Cancer Diagnosis Application,” Eur. J. Oper. Res., vol. 162, no. 2, pp. 532-551, 2005.

[4]F. D. Davis, "User Acceptance of Information Technology: System Characteristics, User Perceptions and Behavioral Impacts," International Journal of Man-Machine Studies, vol. 38, no. 3. pp. 475-487, 1993.

[5]T. A. Horan, B. Tulu, B. Hilton, and J. Burton, "Use of Online Systems in Clinical Medical Assessments: An Analysis of Physician Acceptance of Online Disability Evaluation Systems," in The 37th Hawaii International Conference on System Sciences, 2004.

[6]K. Zheng, "Design, Implementation, User Acceptance, and Evaluation of a Clinical Decision Support System for Evidence-Based Medicine Practice," 2006.

[7]B. A. Y. Al-Nassar, M. S. Abdullah, and W. R. S. Osman, "Overcoming challenges to us e Electronic Medical Records System (EMRs) in Jordan Hospitals,” IJCSNS Int. J. Comput. Sci. Netw. Secur., vol. 11, no. 8, pp. 51-58, 2011.

[8]L. M. Gallant, C. Irizarry, and G. M. Boone, "Exploring the Technology Adoption Needs of Patients Using E-Health," in Health Information Systems: Concepts, Methodologies, Tools, and Applications, 2010, p. 16.

[9]P. Esmaeilzadeh, M. Sambasivan, N. Kumar, and H. Nezakati, "The effect of knowledge sharing on technology acceptance among physicians," Glob. Adv. Res. J. Eng. Technol. Innov., vol. 2, no. 2, pp. 48-57, 2013.

[10]R. Martin, J. Zhang, and C. Liu, "Dempster-Shafer Theory and Statistical Inference with Weak Beliefs," Stat. Sci., vol. 25, no. 1, pp. 72-87, 2010.

[11]F. D. Davis, "Perceived Usefulness , Perceived Ease of Use , and User Acceptance of lnformation Technology," Technology, vol. 13, no. 3, pp. 319-340, 1989. 